\title{
The Time-Varying Effects of Monetary Policy on House Prices in China: An Application of TVP-VAR Model with Stochastic Volatility
}

\author{
Weina Cai ${ }^{1} \&$ Sen Wang ${ }^{2}$ \\ ${ }^{1}$ College of Economics, Jinan University, Guangzhou, China \\ ${ }^{2}$ International Business School, Jinan University, Zhuhai, China \\ Correspondence: Weina Cai, College of Economics, Jinan University, Guangzhou 510632, China. E-mail: \\ vina.tsai@outlook.com
}

Received: January 28, 2018

doi:10.5539/ijbm.v13n4p149

\author{
Accepted: February 26, 2018 \\ Online Published: March 18, 2018 \\ URL: https://doi.org/10.5539/ijbm.v13n4p149
}

\begin{abstract}
The boom of housing market in China in recent years has attracted great concerns from all over the world. How monetary policy affects house prices in China becomes an essential topic. This paper studies the time-varying effects of monetary policy on house prices in China during 2005.7-2017.10, by using a time-varying parameter VAR model. This paper obtains three interesting results. First, there are time-varying features of the responses of house prices to monetary policy shocks half-year and 1-year ahead, no matter through interest rate channel or through credit channel. Second, interest rate channel and credit channel have been enhanced since financial crisis in 2008. Third, the responses of nominal house prices to monetary policy in China are mainly driven by the responses of real house prices, instead of inflation. Finally, this paper gives proper suggestions for each finding respectively to central bank in China.
\end{abstract}

Keywords: house prices, monetary policy, time-varying effects, TVP-VAR model

\section{Introduction}

Since the financial crisis in 2008, a great attention has been paid to how monetary policy should properly control house prices. With the turmoil, monetary policy was executed to inject large liquidity into the credit market and real activity market globally. However, the released monetary liquidity in China kept flowing into high-returned markets, especially housing market. The growth rates of house prices and investment both increased rapidly. This circumstance makes most people unable to afford housing. It seems that policymaker tries to control house prices with monetary policy, and as a result, "price puzzle" (Note 1) arose. However, in fact, central bank in China does not target house prices, even when there are the skyrocketing house prices. The lasting slack real activity in China pushes policymaker to conduct a looser monetary policy for a long time; and there is tight credit policy targeting housing market. These two directions of policies were conducted simultaneously, together influencing housing market.

As Min Zhu said, housing market plays an important role in financial stability and real economy. In particular, monetary policy is important to regulate house price bubble coincided with credit boom (Note 2). Generally, in China, real estate developers mainly finance from banks through on-balance sheet; since the continuous rising of house prices, central bank confined banks to make loans to real estate developers, for example, through higher credit costs. However, with adequate liquidity, banks found other ways through off-balance sheet to finance them, such as trust funds or other wealth management products. Consequently, higher interest rate turns out to have limited effects on loans to housing market. One of the reasons is that housing market in China has been developed sharply in recent decades, leading to a far higher return of housing investment than credit cost (Tan and Wang, 2015). Adequate liquidity attracted bankers continuing to lend money to real estate developers. And real estate developers would decide to require loans by comparing their investment return and credit costs, so would households who want to consume or invest housing. Therefore, interest rate and money supply instrumented by the People's Bank of China, PBC hereafter, would influence house prices together.

In particular, since 1996, there were several policies in China to facilitate the reform of interest rate liberalization (Note 3). Also, the development of credit market and the awareness of credit-consumption in China increase the use of housing mortgage, which in turn enhances the financial feature of house and the role of housing market in 
monetary policy transmission mechanism. Moreover, since the financial crisis, the uncertainty is rising globally, inducing more uncertainties for economic development. These factors would be the reasons to make monetary policy transmission mechanism varying in terms of house prices. Unfortunately, so far this important fact has not been noticed. Therefore, to better integrate with reality, this paper will unfold by a time-varying parameter VAR model to study whether and how the responses of house prices to monetary policy in China would change over time.

\section{Literature Review}

This paper analyzes the relationship between monetary policy and house prices in China. Literatures show an unstable relationship between them (Wang and Han, 2009; Lee et al., 2011; Jia et al., 2014; Chen et al., 2016). Especially, the effects of monetary policy on house prices were different by the change of economic environment (Jia et al., 2016; Chen et al., 2016). The most recent development of housing market may cause an uncertainty of house-related transmission mechanism channels (Mishkin, 2007). Consequently, when considering the fact that China has experienced a rapid development of housing market and also a shifting macroeconomic environment from high growth to The New Normal, the effect of monetary policy on house prices faces many changing circumstances, which would make it varying over time.

Intuitively, there are two major channels of transmission mechanism referring to controlling housing market in China: interest rate channel and credit channel. In detail, for interest rate channel, tight money policy lifts real interest rate, causing an increase of capital cost, and, therefore, reducing investment spending and then the aggregate demand and output (Mishkin, 1995). In particular, short-term and long-term interest rate have different effects on house prices; the response of house prices to short-term interest rate is stronger and longer than that to long-term interest rate (Bernanke and Gertler, 1995; Bjornland and Jacobsen, 2010). Also, the type of housing, such as the middle-, luxury- and affordable-segments in housing market, could influence the effects of interest rate (Gupta, Jurgilas and Kabundi, 2010). For credit channel, there are several ways to work out, such as the bank lending channel and the balance-sheet channel (Bernanke and Gertler, 1995). Obviously, the bank-lending channel is applied to the behavior of banks discussed above; similarly, the balance-sheet channel explains the behavior of real estate developers and households mentioned above. Performed as a collateral, house itself plays an essential role in consuming and investing housing, making the effects of monetary policy on house prices more significant (Aoki et al., 2004; Iacoviello, 2005; Calza et al., 2013). Moreover, financial system liberalizations, housing credit system and the development of mortgage market influence the effects of monetary policy on house prices (Goodhart and Hofmann, 2008; Iacoviello and Minetti, 2008; Calza, Monacelli and Stracca, 2013). Surprisingly, by dividing the sample into two sub-periods, Iacoviello and Neri (2010) find that the influence of monetary policy through credit market on house prices was getting stronger in America. Consequently, interest rate channel and credit channel have essential impacts on monetary policy transmission mechanism in terms of housing market.

Nevertheless, there is few to consider the changing effects of monetary policy on house prices; most of them ignore an important fact that this relationship is unstable. To capture the time-varying feature of the responses of house prices to monetary policy, time-varying parameter VAR model would be used. Besides, to avoid the common issue of over-parameterized among most time-varying parameter VARs, this paper will use a time-varying parameter VAR model with stochastic volatility (Nakajima, 2011). It allows the VAR coefficients, a block which relates to the error variances and another relating to error co-variances to evolve by themselves. In a word, this paper tries to explain whether and how the response of house prices to monetary policy changes over time in China.

\section{Model}

This paper refers to Nakajima (2011) for the time-varying parameter VAR model. To introduce TVP-VAR model with stochastic volatility, this paper starts with the basic VAR model defined as

$$
A y_{t}=B_{1} y_{t-1}+\cdots+B_{i} y_{t-i}+u_{t}, \quad t=i+1, \cdots, n,
$$

where $y_{t}$ is the $p \times 1$ vector of observed variables, and $A, B_{1}, \cdots, B_{i}$ are $p \times p$ matrices of coefficients. The disturbance $u_{t}$ is a $p \times 1$ structural shock and, it is assumed that $u_{t} \sim N(0, \Sigma \Sigma)$, where

$$
\Sigma=\left(\begin{array}{cccc}
\sigma_{1} & 0 & \cdots & 0 \\
0 & \ddots & \ddots & \vdots \\
\vdots & \ddots & \ddots & 0 \\
0 & \cdots & 0 & \sigma_{p}
\end{array}\right)
$$

Also, it is specified as the simultaneous relations of the structural shock by recursive identification, and assumes 
that $A$ is lower-triangular,

$$
A=\left(\begin{array}{cccc}
1 & 0 & \cdots & 0 \\
a_{21} & \ddots & \ddots & \vdots \\
\vdots & \ddots & \ddots & 0 \\
a_{p 1} & \cdots & a_{p, p-1} & 1
\end{array}\right)
$$

Therefore, model (1) could be rewritten as follows:

$$
y_{t}=C_{1} y_{t-1}+\cdots+C_{i} y_{t-i}+A^{-1} \sum \varepsilon_{t}, \quad \varepsilon_{t} \sim N\left(0, I_{k}\right),
$$

where $C_{j}=A^{-1} B_{j}$, for $j=1, \cdots, i$. By stacking the elements in the rows of $C_{j}$ 's to construct $\beta\left(p^{2} i \times 1\right.$ vector), and defining $X_{t}=I_{k} \otimes\left(y_{t-1}^{\prime}, \cdots, y_{t-i}^{\prime}\right)$, where $\otimes$ refers to the Kronecker product, the model could be rewritten as follows:

$$
y_{t}=X_{t} \beta+A^{-1} \sum \varepsilon_{t} .
$$

Until now, the parameters in model (3) are all time-invariant. In this case, it should be extended to the TVP-VAR model by allowing those parameters to be time-variant. Therefore, consider the TVP-VAR model with stochastic volatility defined by

$$
y_{t}=X_{t} \beta_{t}+A_{t}^{-1} \sum_{t} \varepsilon_{t}, \quad t=i+1, \cdots, n,
$$

where the coefficients $\beta_{t}$, and the parameters $A_{t}$ and $\sum_{t}$ are all time varying. Specifically, variables are defined to include intercepts as $X_{t}=I_{k} \otimes\left(1, y_{t-1}^{\prime}, \cdots, y_{t-i}^{\prime}\right)$, where the intercepts are also time-varying. Following Primiceri (2005), let $a_{t}=\left(a_{21}, a_{31}, \cdots, a_{k, k-1}\right)^{\prime}$ be a stacked vector of the lower-triangular elements in $A_{t}$ and $g_{t}=\left(g_{1 t}, \cdots, g_{p t}\right)^{\prime}$ with $g_{j t}=\log \sigma_{j t}^{2}$, for $j=1, \cdots, p, t=i+1, \cdots, n$. And then assume the parameters in model (4) to follow a random walk process as follows:

$$
\begin{gathered}
\beta_{t+1}=\beta_{t}+u_{\beta t}, a_{t+1}=a_{t}+u_{a t}, g_{t+1}=g_{t}+u_{g t}, \\
\left(\begin{array}{c}
\varepsilon_{t} \\
u_{\beta t} \\
u_{a t} \\
u_{g t}
\end{array}\right) \sim N\left(0, \quad\left(\begin{array}{cccc}
I & 0 & 0 & 0 \\
O & \sum_{\beta} & 0 & 0 \\
0 & O & \sum_{a} & 0 \\
O & 0 & 0 & \sum_{g}
\end{array}\right)\right),
\end{gathered}
$$

for $t=i+1, \cdots, n$, where $\beta_{i+1} \sim N\left(\mu_{\beta 0}, \sum_{\beta 0}\right), a_{i+1} \sim N\left(\mu_{a 0}, \sum_{a 0}\right), g_{i+1} \sim N\left(\mu_{g 0}, \sum_{g 0}\right)$.

\section{Data and Settings}

This paper uses 5-variable TVP-VAR model to estimate monthly data from 2005.07 to 2017.10 in China. The variable vector is defined as $y_{t}=\left(I P_{t}, C P I_{t}, I R_{t}, M 2_{t}, H P_{t}\right)$, where $I P$ refers to Y-o-Y growth of industrial production, $C P I$ to Y-o-Y growth of consumer price level, $I R$ to real one-year loan rate (Note 4), $M 2$ to Y-o-Y growth of broad money, and HP to Y-o-Y growth of real house prices of 70 median \& large cities in China. Data of industrial production in China are missing for every first two-month in the official website (National Bureau of Statistics of China, hereafter, NBSC), but DataStream offers the complete data series. Therefore, here adopts the Industrial Production data from DataStream. The real loan rate, $I R$, offered by the People's Bank of China, is calculated by nominal one-year loan rate minus inflation. Similar treatment is taken to real house prices, HP. Except for industrial production and interest rate, other data could be found in NBSC. Although the sample duration, from Jul 2005 to Oct 2017, depends on the availability of house price data, it captures the most representative period when housing market in China has experienced sharp development with cyclical and shifting characters.

Variable setting is $y_{t}=\left(I P_{t}, C P I_{t}, I R_{t}, M 2_{t}, H P_{t}\right)$; the number of TVP-VAR lags is two. It is based on the result of BIC for the simple VAR model. And $\sum_{\beta}$ is assumed to be diagonal matrix and the assumptions of initial values and prior distribution of parameters are following Nakajima's settings (Note 5). This paper also conducts the MCMC algorithm by drawing $M=20,000$ samples after discarding the initial 1,000 samples in the burn-in period, to obtain posterior draws. Finally, this paper builds impulse response functions to depict how large and how long monetary policy influences house prices, such as the effects of monetary policy at several periods ahead on house prices and at some significant moments when monetary policy in China experienced sharp change, which may induce the enormous shifts of housing market. 


\section{Results}

\subsection{Parameter Estimation}

Table 1. Estimation of parameters in the TVP-VAR Model

\begin{tabular}{cllllll}
\hline Parameter & Mean & Stdev & $95 \% \mathrm{U}$ & $95 \% \mathrm{~L}$ & Geweke & Inef. \\
\hline$\left(\Sigma_{\beta}\right)_{1}$ & 0.0023 & 0.0003 & 0.0018 & 0.0029 & 0.873 & 7.11 \\
$\left(\Sigma_{\beta}\right)_{2}$ & 0.0023 & 0.0003 & 0.0018 & 0.0029 & 0.966 & 9.59 \\
$\left(\Sigma_{a}\right)_{1}$ & 0.0052 & 0.0013 & 0.0034 & 0.0081 & 0.129 & 28.72 \\
$\left(\Sigma_{a}\right)_{2}$ & 0.0046 & 0.0012 & 0.003 & 0.0076 & 0.38 & 41.05 \\
$\left(\Sigma_{g}\right)_{1}$ & 1.1971 & 0.1934 & 0.8467 & 1.6107 & 0.57 & 17.93 \\
$\left(\Sigma_{g}\right)_{2}$ & 0.006 & 0.0024 & 0.0034 & 0.0122 & 0.127 & 100.1 \\
\hline
\end{tabular}

Note. The estimates of $\Sigma_{\beta}, \Sigma_{a}$ are multiplied by 100 .

Table 1 shows the estimated results of parameters in the TVP-VAR model, including the distribution of posteriors, the convergence diagnostics of Geweke (1991), and inefficient factors computed by using MCMC sampling. In the estimated results, all Geweke values are less than the 5\% significance level based on the convergence diagnostics, 1.96, indicating that the null hypothesis of convergence to the posterior distribution is not rejected. Also, the inefficient factors are rather low, implying that the number of efficient samples for parameters and state variables are sufficient, say, minimum around $M / 100=200$.

Figure 1 successively illustrates sample autocorrelation, sample paths, and posterior densities of parameters for each row. The sample autocorrelations at the first row quickly decrease and keep slightly ranging around 0 level, suggesting that most samples are low auto-correlated. The sample paths at the second row are very stable, indicating that the samples produced from MCMC method are efficient.

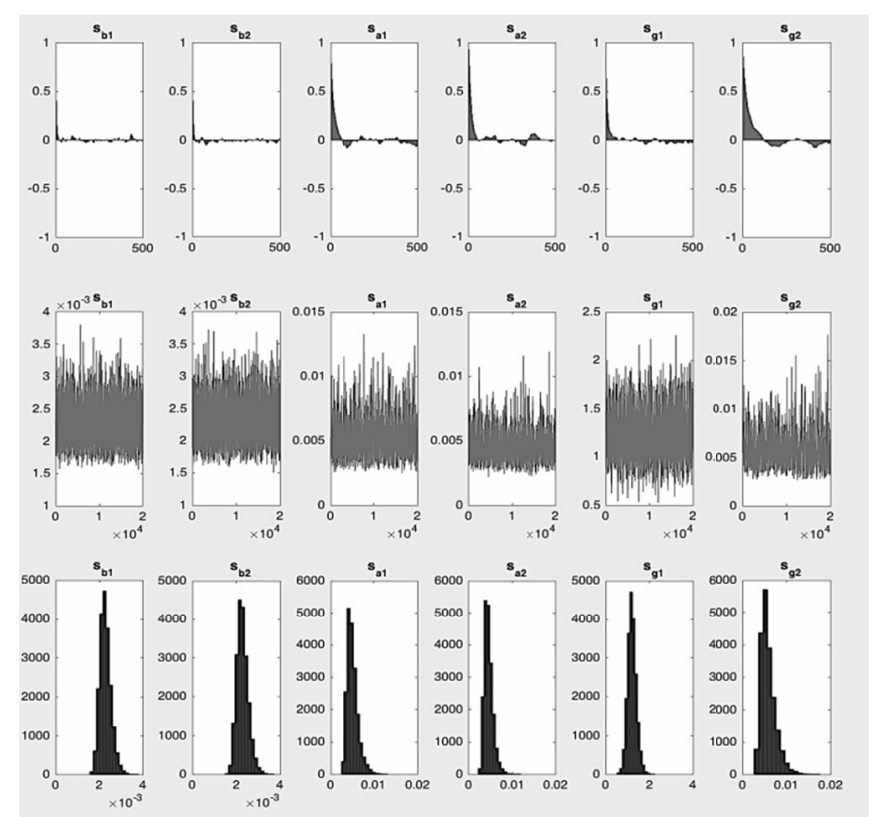

Figure 1. Estimation Results of Parameters in the TVP-VAR Model

Note. The first row refers to sample autocorrelation; the second row to sample paths; the third row to posterior densities. The estimates of $\Sigma_{\beta}$, $\Sigma_{a}$ are multiplied by 100 .

\subsection{Impulse Responses}

This paper mainly focuses on the responses of house prices to interest rate and money supply. Firstly, it chooses shocks arising at 3 different periods ahead in terms of the responses of variables at every time point: 1-quarter, 
half-year and 1-year. In figure 2, it is apparent that the responses of house prices to interest rate and money supply show significant time-varying features, except interest rate shocks 1-quarter and half-year ahead on house prices. The negative effects of interest rate 1-year ahead are around $-1 \%$ and keep stable before the mid of 2008; instead, from the second half of 2008 until the mid of 2014, the size of the negative responses of house prices continues to increase, from $-1 \%$ to $-6 \%$, and then keeps unchanged until the end of the sample period, the end of 2017. When considering the fact that the Chinese economy was badly influenced by the financial crisis in the mid of 2008 and Chinese Government took actions to confine its shock immediately, it is interesting to find that the financial crisis possibly enhances the negative responses of house prices to interest rate shocks long-term ahead. It also suggests that the macro-economic uncertainty would largely change interest rate channel of monetary policy transmission mechanism in China. Besides, the stable responses of house prices to interest rate after the mid of 2014 imply that the interest rate channel in China has been stable recently. Although the time-varying feature is not significant, shocks of interest rate 1-quarter and half-year ahead are remarkable, ranging between $-12.5 \%$ and $-15 \%$. Nevertheless, shocks of interest rate half-year ahead have largest impact on house prices overall; the second rank is 1-quarter ahead, and the last is half-year ahead.
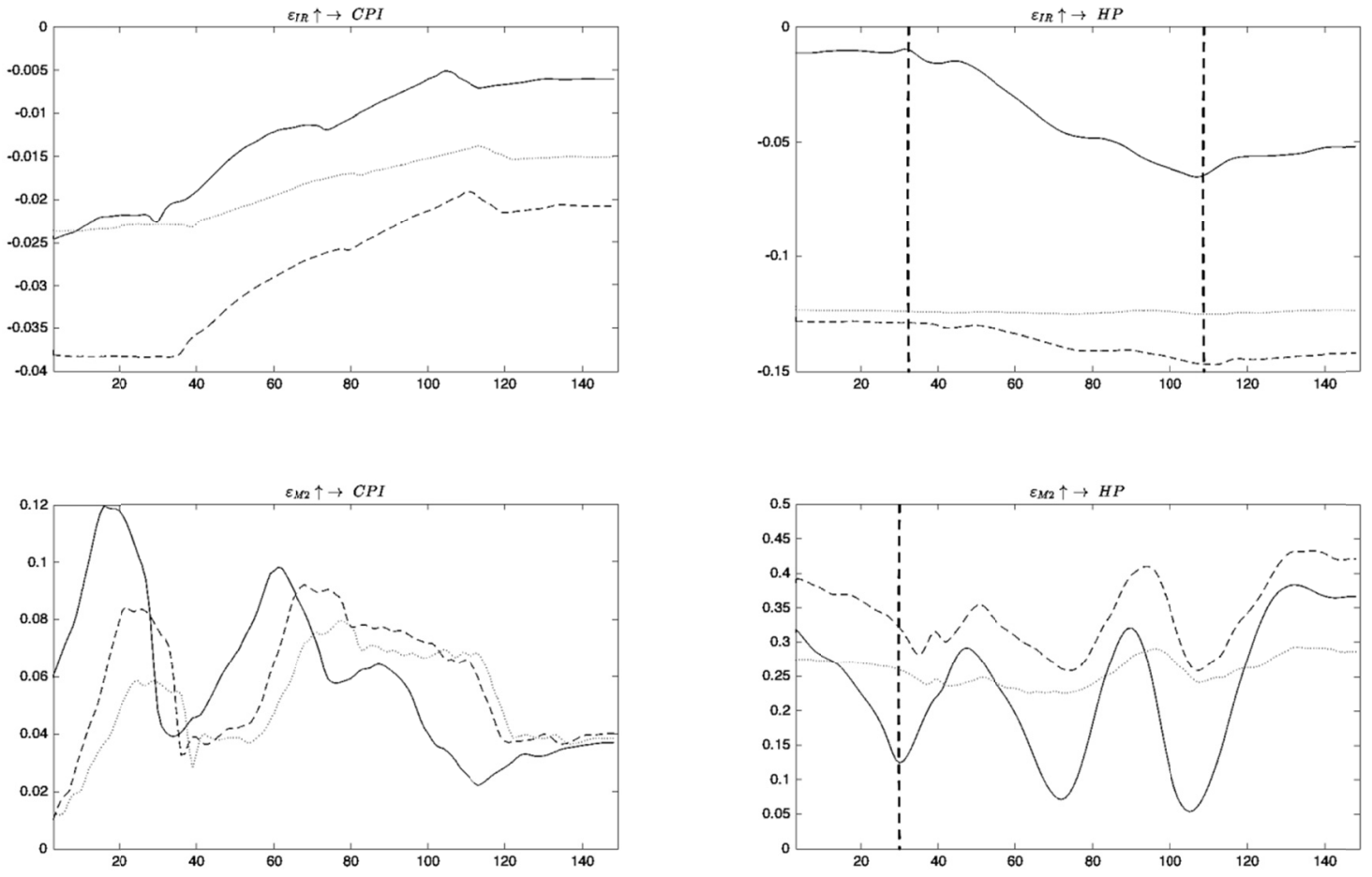

Figure 2. Impulse Responses from Shocks Three Different Periods Ahead

Note. the solid line refers to impulse responses from shocks 1 quarter ahead; the dashed line refers to half-year ahead; the dotted line refers to 1 -year ahead. There are several vertical dashed lines to identify the time point of the change of impulse response.

Next, as for the positive effects of money supply on house prices in China, there are obvious switching and cyclical trends in terms of half-year and 1-year ahead. However, it is intuitive to see that they both increase to have a larger size of switching range over time, especially after the end of 2007 , between $28 \%$ and $43 \%$ for half-year ahead and between $13 \%$ and $38 \%$ for 1 -year ahead respectively. Given that housing market in China experienced the first boom period in 2007 and so did the mortgage market, it is obvious to see that the credit channel of monetary policy transmission mechanism in China has been developed since 2007. Moreover, central bank in China and Chinese Government conducted the project to release 4 trillion Yuan to cope with the financial crisis, finally stimulating the prosperity in housing market. This result also illustrates that the financialization of housing market in China has been continued since the end of 2007, strengthening the role played by financial accelerator in the credit channel to housing market in China. As for the shocks 1-quarter ahead, they softly change between $25 \%$ and $30 \%$, indicating modest time-varying feature.

In addition, paying attention to the impacts of monetary policy on CPI, it is really interesting to see that the negative influences of interest rate are continuously decreased during the whole sample period, no matter which 
kind of shocks. Similar results could be found in the effects of money supply on CPI. Besides, the size of responses from CPI is rather smaller than that from real house prices. When considering the way to get the real house price index, it is clear to conclude that the increasing responses of house price index to monetary policy in China is mainly driven by those of real house prices, instead of inflation.

Secondly, it chooses shocks arising at 3 different time points to affect house prices: 2008.12, 2011.04 and 2014.11. Intuitively, the horizon of impulse response is 24 months. The reason why choosing these three time points are as following: the financial crisis hit economic activity in China at the mid of 2008, and then the government reacted to release 4 trillion liquidities to the market, but mostly transferring to housing market since the end of 2008; after the high reaching of inflation, PBC conducted tight monetary policy from second to third quarter of 2011, which is noteworthy when seeing the fact that monetary policy in China after financial crisis mostly was loose; even though the skyrocketing house prices has been controlled during the first half of 2014, the collapse of stock market at the mid of 2014 drives government to conduct a rather loose monetary policy to save the market, in which the size is significant around the end of 2014. Figure 3 shows the details.
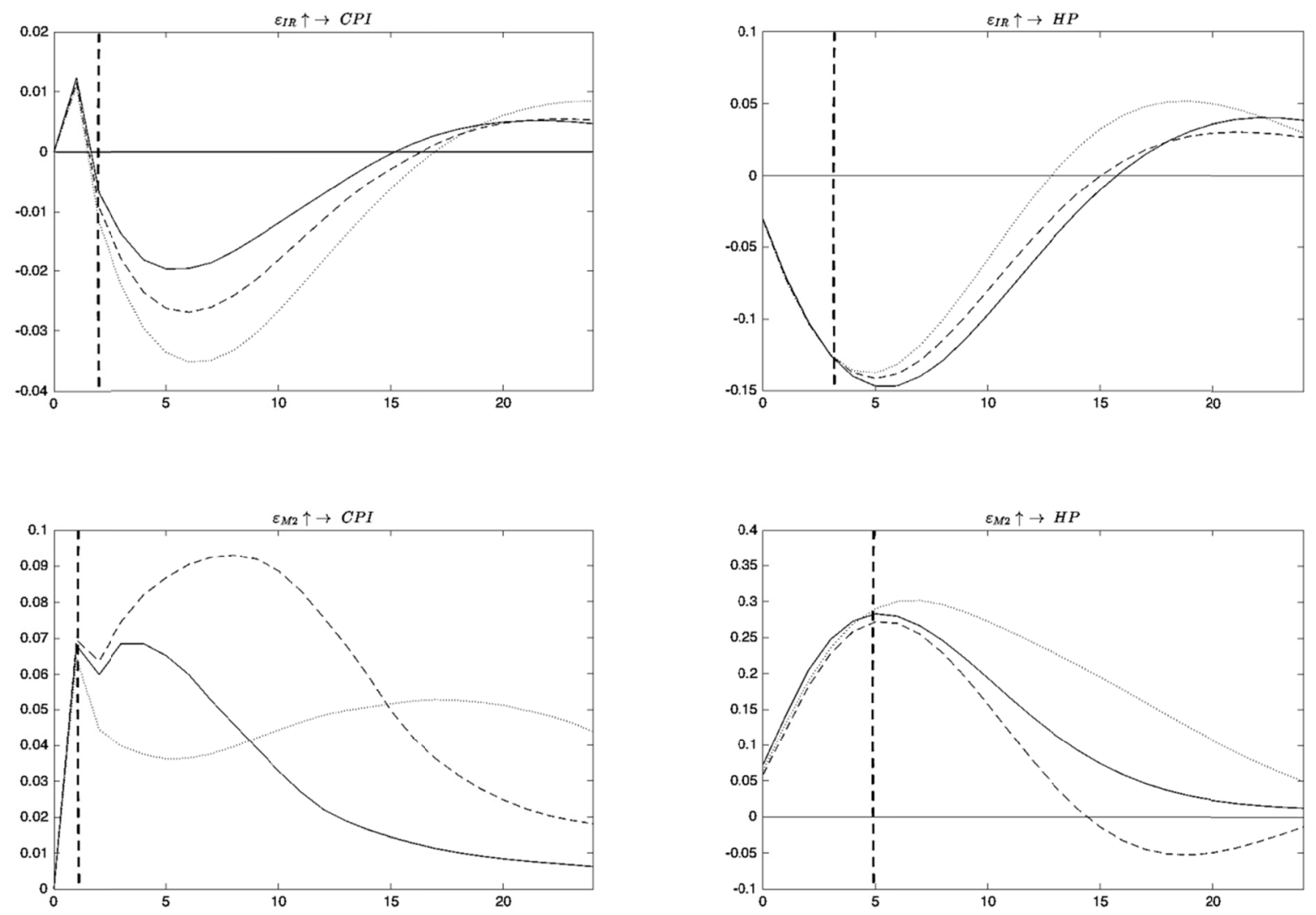

Figure 3. Impulse responses from shocks at three different time points

Note. The solid line refers to impulse responses from shocks in Dec., 2008; the dashed line refers to Apr., 2011; the dotted line refers to Nov., 2014. There are several vertical dashed lines to identify the time point of the change of impulse response.

In figure 3 , it is surprised to see that these three time points have more different impulse responses during most periods; in other words, at these three time points, the responses of house prices illustrate time-variant feature. The negative impacts of interest rate on house prices reach highest point after 3 months, about $-15 \%$, then decrease separately, and finally turn to be positive after 1 year. The later time point, the stronger negative impacts. Similarly, the positive impacts of money supply on house prices increase to top point after 5 months, around 28\% (except for those in 2008.12, which reach top at around 6 months), and then decrease slowly to 0 (those in 2011.4 turn to be negative after 14 months). However, in this case, money supply shocks in 2008.12 have more powerful impacts on house prices, whereas those in 2014.11 and 2011.04 have lower rankings successively. It verifies the conclusion in figure 2 that the financial crisis increases the influences of interest rate channel and the financialization of housing market in China also enhances the role of credit channel, when 
considering the impacts of monetary policy on house prices in China. Moreover, the results in figure 3 suggest that at the selected time points, monetary policy has different impacts on house prices between 5 months and 24 months, but similar impacts before 3 months. Consequently, the results of impulse responses in figure 2 and figure 3 are consistent: shocks 1-quarter ahead have more characteristics of time-invariant; shocks half-year and 1 -year ahead have more feature of time-variant.

Similarly, the responses of CPI to monetary policy, interest rate and money supply, are rather smaller than contemporaneous response of real house prices, no matter in 2008.12, 2011.04 or 2014.11. This result is also consistent to that in figure 2 .

\section{Conclusions}

\subsection{Conclusions and Suggestions}

This paper uses TVP-VAR model with stochastic volatility to study the time-varying effects of monetary policy on house prices in China during 2005.7-2017.10. There are several findings in the paper:

First, there are time-varying features for responses of house prices to monetary policy shocks half-year and 1-year ahead, no matter through interest rate channel or through credit channel. Considering some distinct time points, it is obvious to conclude that financial crisis works importantly to the time-varying influences of monetary policy, through interest rate channel and credit channel, on real house prices in China. When central bank in China expects to control house prices, it should take into account the time-variant feature of interest rate channel and credit channel and the timing and magnitude of their impacts.

Second, interest rate channel and credit channel have been enhanced since financial crisis in 2008. This paper finds that the additive productions of financial crisis in 2008, including the uncertainty of macroeconomic environment and the financialization of housing market and the development of mortgage market in China, are the potential reasons why monetary policy have time-varying effects on house prices, both through interest rate channel and credit channel. This finding confirms the conclusion of (Aoki et al., 2004; Iacoviello, 2005; Iacoviello and Minetti, 2008; Calza, Monacelli and Stracca, 2013). Meanwhile, it could be an alert for central bank in China about the broad influences of uncertainty from macro-economic environment and of the transforming of housing market.

Third, the responses of nominal house prices to monetary policy in China are mainly driven by the responses of real house prices, instead of inflation. Although it is significant that monetary policy plays a great role in the skyrocketing house prices recently, it is crucial to clarify the more responsive one to monetary policy is real house prices, instead of inflation. In this case, when conducting monetary policy to adjust inflation, central bank in China should consider its accompanying results, such as more responsive real house prices.

\subsection{Future study and limitations}

This paper has found the time-varying effects of monetary policy on house prices in China from 2005.7 to 2017.10, by using the TVP-VAR model. Nevertheless, this paper did not offer more evidence or dig more about the reason why the time-varying effects of monetary policy happened during this period. Is it because the economic reform in China changed the macroeconomic environment and then changed the transmission mechanism of monetary policy? Or because the different regimes of business cycle have different transmission mechanism of monetary policy? And this could be the future direction for this paper issue to study.

\section{References}

Aoki, K., Proudman, J., \& Vlieghe, G. (2004). House prices, consumption, and monetary policy: A financial accelerator approach. Journal of Financial Intermediation, 13(4), 414-435. https://doi.org/10.1016/j.jfi.2004.06.003

Bernanke, B. S., \& Gertler, M. (1995). Inside the black box: the credit channel of monetary policy transmission (No. w5146). National Bureau of Economic Research. https://doi.org/10.1257/jep.9.4.27

Bjørnland, H. C., \& Jacobsen, D. H. (2010). The role of house prices in the monetary policy transmission mechanism in small open economies. Journal of Financial Stability, 6(4), 218-229. https://doi.org/10.1016/j.jfs.2010.02.001

Calza, A., Monacelli, T., \& Stracca, L. (2013). Housing finance and monetary policy. Journal of the European Economic Association, 11(s1), 101-122. https://doi.org/10.1111/j.1542-4774.2012.01095.x

Chen, S., \& Wang, X. (2016). Financial Costs, House prices Fluctuation and Monetary Policy Transmission. Journal of Financial Research, (3), 1-14. 
Geweke, J. (1991). Evaluating the accuracy of sampling-based approaches to the calculation of posterior moments (Vol. 196). Minneapolis, MN, USA: Federal Reserve Bank of Minneapolis, Research Department.

Goodhart, C., \& Hofmann, B. (2008). House prices, money, credit, and the macroeconomy. Oxford Review of Economic Policy, 24(1), 180-205. https://doi.org/10.1093/oxrep/grn009

Gupta, R., Jurgilas, M., \& Kabundi, A. (2010). The effect of monetary policy on real house price growth in South Africa: A factor-augmented vector autoregression (FAVAR) approach. Economic Modelling, 27(1), 315-323. https://doi.org/10.1016/j.econmod.2009.09.011

Iacoviello, M. (2005). House prices, borrowing constraints, and monetary policy in the business cycle. The American Economic Review, 95(3), 739-764. DOI: 10.1257/0002828054201477

Iacoviello, M., \& Minetti, R. (2008). The credit channel of monetary policy: Evidence from the housing market. Journal of Macroeconomics, 30(1), 69-96. https://doi.org/10.1016/j.jmacro.2006.12.001

Iacoviello, M., \& Neri, S. (2010). Housing market spillovers: Evidence from an estimated DSGE model. American Economic Journal: Macroeconomics, 2(2), 125-164. https://doi.org/10.1257/mac.2.2.125

Jia, J., \& Qin, C., \& Zhang, J. (2014). Fiscal Policy, Monetary Policy and the Stability of Asset Prices. The Journal of World Economy, (12), 3-26.

Jia, S., \& Dong, Z., \& Chen, W. (2016). Shadow Banking, Monetary Policy and Real Estate Market. Modern Economic Science, 38(3), 13-19+30+124.

Lee, S., \& Chen, R., \& Zhou, J. (2011). Analysis of Characteristics and Money Policy on Real Estate Market. Journal of Financial Research, (6), 33-45.

Mishkin, F. S. (1995). Symposium on the Monetary Transmission Mechanism. The Journal of Economic Perspectives, 9(4), 3-10. https://doi.org/10.1257/jep.9.4.3

Mishkin, F. S. (2007). Housing and the monetary transmission mechanism (No. w13518). National Bureau of Economic Research. https://doi.org/10.3386/w13518

Nakajima, J. (2011). Time-varying parameter VAR model with stochastic volatility: An overview of methodology and empirical applications (No. 11-E-09). Institute for Monetary and Economic Studies, Bank of Japan.

Sheng, S., \& Wu, P. (2008). The Binary Transmission Mechanism of China's Monetary Policy_A Research on the "Two Intermediaries, Two Targets" Model. Economic Research Journal, 43(10), 37-51.

Sims, C. A. (1992). Interpreting the macroeconomic time series facts: The effects of monetary policy. European Economic Review, 36(5), 975-1000. https://doi.org/10.1016/0014-2921(92)90041-T

Tan, Z., \& Wang, C. (2015). The Fluctuation of House Prices, Stance and Response of Monetary Policy. Economic Research Journal, (1), 67-83.

Wang, Q., \& Han, X. (2009). Can Monetary Policy Target on Asset Price? Evidence from Chinese Real Estate Market. Journal of Financial Research, (8), 114-123.

\section{Notes}

Note 1. Theoretically, CPI decreases when interest rates increase; instead, during $60 \mathrm{~s}-70 \mathrm{~s}$, there was a positive relationship between federal funds rate and inflation in America. This is called "price puzzle". See Sims (1992).

Note 2. http://www.imf.org/external/np/speeches/2014/060514.htm

Note 3. http://www.frbsf.org/banking/files/Asia-Focus-China-Interest-Rate-Liberalization.pdf

Note 4. Although the nominal one-year loan rate is set by central bank in China, its power to affect real activity is sufficiently larger than interbank rate, which is fully flexible in China (Sheng and $\mathrm{Wu}, 2005$ ). Therefore, this paper chooses one-year loan rate as proxy of interest rate for monetary policy in China. Nevertheless, the real one-year loan rate would be used.

Note 5. Nakajiima (2011) points out that, when comparing with the non-diagonal matrix, some researches illustrate that the results are not sensitive to this assumption. 


\section{Copyrights}

Copyright for this article is retained by the author(s), with first publication rights granted to the journal.

This is an open-access article distributed under the terms and conditions of the Creative Commons Attribution license (http://creativecommons.org/licenses/by/4.0/). 